\title{
Multi Period Auction Incorporating Complex Bids and Network Technical Constraints
}

\author{
${ }^{(1)}$ Bruno André Gomes, ${ }^{(*)}$ João Tomé Saraiva, member IEEE \\ ${ }^{(1)}$ INESC Porto - Instituto de Engenharia de Sistemas \\ e Computadores do Porto, Campus da FEUP, Rua Dr. Roberto Frias, 4200-465 Porto, Portugal, bagomes@inescporto.pt \\ ${ }^{(*)}$ FEUP/DEEC - Faculdade de Engenharia da Univ. do Porto and INESC Porto - Instituto de Engenharia de Sistemas \\ e Computadores do Porto, Campus da FEUP, Rua Dr. Roberto Frias, 4200-465 Porto, Portugal
}

\begin{abstract}
This paper presents an integrated model to deal with complex bids and network security constraints in electricity markets. Apart from purely economic aspects, power systems operation is also driven by technical issues that quite often turn unfeasible purely economic schedules. This is the case of up and down ramps and minimum technical limits of generators, nodal voltage ranges and branch flow limits. The activities of the Market and System Operators are quite often organized in terms of a sequential set of actions that may not guarantee identifying the best global solution. This suggests addressing the problem in a more integrated way and adopting a well known optimization technique, as Simulated Annealing. This paper describes the mathematical formulation of the problem, the adopted solution algorithm and details a case study based on the IEEE 24 bus/38 branch system.
\end{abstract}

Keywords: electricity markets, multi-period auctions, complex bids, Simulated Annealing.

\section{INTRODUCTION}

In the scope of the restructuring process experienced by power systems in recent decades, vertically integrated utilities were unbundled and we can now identify a number of activities and a set of new agents in the sector. Among them we can mention generation (either under normal or special regulated regime namely to subsidize renewables), network transmission and distribution activities, retailing activities, and coordination and regulatory activities. Coordination activities are usually related with centralized markets typically managed by Market Operators and technical operation usually assigned to ISO's. In several countries ISO's and the transmission providers are merged in a single entity, the TSO, that are responsible for ensuring the secure operation of the system.

The set of injections coming from the MO and from bilateral contracts corresponds to what agents aim at physically implementing in the network. However, network operation is constrained by physical laws and this set of injections can be unfeasible, for instance because there are over flows leading to congestion problems or voltages out of their admissible range. Apart from this, the simplest auction format is based on simple bid uniform price auctions in which market agents transmit their simple bids including only pairs (quantity ; price). However, in practice, generators can have up-ramp and down-ramp limits, minimum generation values and also fixed start-up and shut-down costs so that the simple bid format is not adequate to model all these aspects. When all these issues are considered, the 24 hourly simple bid dispatches for the next day can eventually be unfeasible since they can originate violations of several constraints directly related with the operation of generators. Even if one obtains a feasible dispatch considering generator constraints, it is still possible that violations of network operation and security constraints arise. One should realize that changing the dispatch of an hour to solve a particular constraint then create new violations. This suggests that the MO and the TSO should work closely to identify the most adequate solution, while enforcing all the constraints and that ultimately the 24 hour dispatches should in fact be treated in a coupled way.

The literature includes a large number of publications addressing congestion management issues, cost allocation and the evaluation of the impact of congestion on bidding strategies as addressed in [1]. Regarding congestion management, one can adopt nodal or zonal marginal pricing as described in [2] and in [3] while Oren and Ross in [4] and Mendez and Rudnick in [5] propose the use of bilateral contracts, flow gate rights or transmission rights.

Apart from congestion problems, the simple auction models described above have long been studied and enlarged in several ways. For instance, [6] describes an OPF bid based algorithm taking into account the AC power flow equations and [7] describes a clearing tool integrating up-ramp and down-ramp limits using a mixed-integer model. In reference [8] it is maximized the Social Welfare Function for a single auction period not considering time coupling constraints and [9] describes an OPF based algorithm to solve power system constraints in a coupled way along 24 hours based on an initial feasibility stage and on a subsequent second step to fine tuning voltage control resources running OPF problems.

Having in mind the available approaches to model auction problems, we developed an optimization problem that takes the purely economic hourly dispatches identified by the MO as the initial solution. These hourly dispatches based on simple bids display the maximum value of the Social Welfare Function, SWF. If generator complexity constraints leading to time couplings or network constraints are violated, it is run a Simulated Annealing based algorithm that aims at minimizing the difference of the values of the SWF in the initial optimal but unfeasible solution and in the final solution. This search strategy was 
chosen since the initial dispatch is the optimum from a pure economic point of view and so it should be changed as little as possible and only if required by technical issues.

The remaining of this paper is organized as follows. Section II presents a brief overview about Simulated Annealing and Section III details the activities of MO's and TSO's. Section IV presents the complexity conditions considered in this work and details the mathematical formulation of the multiperiod auction. Section V describes the adopted Simulated Annealing based solution algorithm. Section VI presents results of a Case Study based on the IEEE 24 bus/38 branch Test System and Section VII draws the most relevant conclusions.

\section{OVERVIEW ON SIMULATED ANNEALING}

Simulated Annealing is a probabilistic based search procedure classified as a Metaheuristics, together with Tabu Search, Genetic Algorithms, Genetic Programming and Particle Swarm Optimization. Simulated Annealing is based on the Metropolis algorithm described by Kirkpatrick [10] and developed by Aarts and Korst [11]. Simulated Annealing is a very powerful and flexible metaheuristic that has been widely applied to combinatorial problems.

In brief, Simulated Annealing starts at an initial solution, $\mathrm{x}_{1}$, evaluates it using the Evaluation Function, EF, selected for the problem under analysis, $\mathrm{f}\left(\mathrm{x}_{1}\right)$, and samples a new solution in the neighborhood of the current one. If the new solution is better than $\mathrm{x}_{1}$, the new solution is accepted. Otherwise, it can still be accepted provided that the probability of accepting worse solutions is larger than a random number. This algorithm is summarized below.

Simulated Annealing Basic Algorithm

i) Initialization: Select an initial solution $x_{1}$ in the solution space X. Evaluate $\mathrm{x}_{1}, \mathrm{f}\left(\mathrm{x}_{1}\right)$;

ii) Assign $\mathrm{x}_{1}$ to $\mathrm{x}^{*}$ and $\mathrm{f}\left(\mathrm{x}_{1}\right)$ to $\mathrm{f}\left(\mathrm{x}^{*}\right)$. The sign $*$ denotes the best solution identified until this step;

iii) Step $n=1,2, \ldots, n . x_{n}$ denotes the current solution at iteration $n$. Obtain a new solution $x$ in the neighborhood of $\mathrm{x}_{\mathrm{n}}$ using a sampling process;

iv) Testing:

a) if $f(x) \leq f\left(x^{*}\right)$, assign $x$ to $x^{*}$ and $f(x)$ to $f\left(x^{*}\right)$;

b) if $f(x) \leq f\left(x_{n}\right)$, assign $x$ to $x_{n+1}$;

else get a random number $p$ in $[0.0 ; 1.0]$ and evaluate $p(n)$, the probability of accepting worse solutions (1). $\mathrm{K}$ is the Boltzman constant and $\mathrm{T}$ is the temperature. if $\mathrm{p} \leq \mathrm{p}(\mathrm{n})$ then assign $\mathrm{x}$ to $\mathrm{x}_{\mathrm{n}+1}$; $p(n)=e^{\frac{E F(x n)-E F(x)}{K . T}}$

v) End if a stopping rule is reached. Otherwise go to iii).

The implementation of this algorithm requires defining the cooling scheme. In most applications it is specified the number of iterations to run at the same temperature level, $\mathrm{T}$. Once this plateau is exhausted, the temperature is lowered by a cooling factor $\alpha$, in $[0.0 ; 1.0]$. According to (1), this means that, in early stages, the probability of accepting worse solutions is larger so that the search can evolve to different areas of the solution space. As the temperature is lowered, it turns more difficult to accept worse solutions meaning that the search is being done in a promising area and one doesn't want to go away from it.

\section{THE MARKET AND SYSTEM OPERATORS}

\section{A. The day-ahead market}

Most restructured power systems include bid based dayahead markets managed by Market Operators. On their simpler versions they are based on Simple Bids that include for each trading hour pairs of available quantity/minimum price one admits to be paid for selling bids, and pairs of quantity/maximum price admitted to be paid for buying bids. Admitting an Uniform Price Auction and not considering coupling constraints, the Market Operator performs 24 hourly separated dispatches each one maximizing the Social Welfare Function, SWF. Selling/buying offers are sorted in ascending /descending order of their bid price. This leads to the calculation of the Market Clearing Quantity, the Market Clearing Price and of SWF interpreted as the area between the buying and selling aggregated curves.

In its simplest version, this auction is formulated by (2) to (5), admitting that each selling bid integrates one only pair (quantity; price). In this model, $\mathrm{C}_{\mathrm{Di}}$ and $\mathrm{C}_{\mathrm{Gj}}$ are the buying and selling prices, $\mathrm{P}_{\mathrm{Di}}$ and $\mathrm{P}_{\mathrm{Gj}}$ are the demand and generation values at the final solution. $\mathrm{P}_{\mathrm{Di}}^{\max }$ and $\mathrm{P}_{\mathrm{Gj}}^{\max }$ are the bid demand and generation quantities while $\mathrm{N}_{\mathrm{D}}$ and $\mathrm{N}_{\mathrm{G}}$ are the number of buying bids and selling bids. Constraints (3) and (4) impose limits to the demand and to the generation available quantities and (5) is the balance equation.

$$
\begin{array}{ll}
\max & \mathrm{Z}=\sum_{\mathrm{i}=1}^{N_{D}} \mathrm{C}_{\mathrm{Di}} \cdot \mathrm{P}_{\mathrm{Di}}-\sum_{\mathrm{j}=1}^{\mathrm{NG}_{\mathrm{G}}} \mathrm{C}_{\mathrm{Gj}} \cdot \mathrm{P}_{\mathrm{Gj}} \\
\text { subj to } & 0 \leq \mathrm{P}_{\mathrm{Di}} \leq \mathrm{P}_{\mathrm{Di}}^{\operatorname{máx}} \\
& 0 \leq \mathrm{P}_{\mathrm{Gj}} \leq \mathrm{P}_{\mathrm{Gj}}^{\operatorname{máx}} \\
& \sum_{\mathrm{i}=1}^{\mathrm{ND}_{\mathrm{D}}} \mathrm{P}_{\mathrm{Di}}=\sum_{\mathrm{j}=1}^{\mathrm{NG}_{\mathrm{G}}} \mathrm{P}_{\mathrm{Gj}}
\end{array}
$$

The Market Operator runs in a separate way as much of these problems as the number of trading periods and then transmits the results to the System Operator. In practice, this independency does not exist because there are several aspects associated to the operation of the generators and network limits that impose that these hourly optimization problems are not separable. Regarding generators, this means going from Simple to Complex Bids to be detailed in Section IV.A.

\section{B. System Operator}

System Operators are responsible for ensuring the secure operation of the power system. Among other aspects, this means performing studies to check if the hourly dispatches identified by the Market Operator together with bilateral contracts lead to technically feasible operation points, 
namely without violating network operation constraints. If these constraints are not violated, the Market Operator schedules and the bilateral contracts can be implemented in each hour of the next day. If violations occur it is necessary to change the schedules, according to the activity rules of the market.

\section{Dealing with infeasibilities}

Infeasibilities can be due to technical generation aspects or to network problems. It is clear that the 24 Market Operator separate dispatches lead to the best ever-possible value of SWF. However, this dispatch can be unfeasible and changing a particular generation at a given hour to solve a constraint can activate other violations. On the other hand, new constraints will never improve the value of SWF. Enforcing a new constraint will reduce the original value (or at most, we will get the same value) of SWF, so that we are getting further away from what was optimal from a pure economic point of view. This reasoning also implies that changes on the original dispatches should be accepted only as far as they were required by technical reasons and the algorithm used to perform these changes should incorporate this concern.

In the case of the Iberian Electricity Market established since 2007 between Portugal and Spain, the solution strategy is detailed in the electricity market code [12]. This document states that in the first place the 24 hour economic schedules are solved ignoring the coupling conditions. Then, the Market Operator checks for the coupling conditions and, if some of them are violated, it successively eliminates bids and substitutes them by bids not yet used until all the conditions are satisfied. Finally, the System Operator checks for the technical feasibility of the 24 hour dispatches. This description suggests that it is used a heuristic based procedure that may not guarantee that SWF is reduced as little as possible when considering complexity conditions. The recognition of this aspect is the most important motivation for this work in terms of developing a more integrated and systematic approach.

\section{MULTI PERIOD AUCTION PROBLEM}

\section{A. Complex Bids}

After addressing the simple bid model, it is now important to identify the complexity conditions to consider. These complexity conditions contribute to turn the problem more realistic but, as a result, they couple the dispatches of different hours. Based on the conditions admitted in the Iberian Electricity market, in the developed model we considered the following complexity conditions:

- indivisibility condition - selling bids can be organized in several blocks (that is, several pairs quantity/price) so that each generator reflects more closely its marginal cost curve. Admitting this block structure, the indivisibility condition states that if a generator bid is accepted, then its first block cannot be dispatched partially. This condition can be used to give information about minimum technical limits of thermal generators;

- minimum income condition - for each day, a generator $\mathrm{j}$ can specify the minimum amount it wants to receive using a fixed term plus a term proportional to the daily allocated energy (6). The fixed term $\mathrm{ft}_{\mathrm{j}}$ (in $€$ ) reflects the start-up and shut-down costs and the variable term $\mathrm{vt}_{\mathrm{j}}$ (in $€ / \mathrm{MWh}$ ) reflects the average generation cost of unit $j$ and it multiplies by the daily energy, Energ ${ }_{j}$, allocated to unit $\mathrm{j}$. This condition holds if the sum of the products of the hourly dispatches of unit $j$ by the hourly Market Prices is larger than the amount given by (6).

$$
\operatorname{Inc}_{\min \mathrm{j}}=\mathrm{ft}_{\mathrm{j}}+\mathrm{vt}_{\mathrm{j}} \text {. Energ }_{\mathrm{j}}
$$

- gradient condition (up and down ramps) - these conditions impose that the power allocated to one generator in two adjacent periods should not display a variation larger than the maximum specified amounts.

\section{B. Formulation of the Problem}

Passing from Simple Bids using one only block (that is one pair quantity/price) per generator, as detailed in Section III.B, to the Complex Bids described in Section 4.1 and admitting several blocks per generator bid leads to a more complete model (7 - 15). In this formulation, $P_{G j m t}$ is the cleared generation of the $m$ block of generator $j$ in period $\mathrm{t}, \mathrm{P}_{\mathrm{Gjmt}}^{\max }$ and $\mathrm{C}_{\mathrm{Gjm}}$ are the bid power and the corresponding bid price, $\mathrm{N}_{\mathrm{G}}$ is number of generators, $\mathrm{MJ}$ is the number of blocks of the bid of generator $\mathrm{j}$ and $\mathrm{u}_{\mathrm{jt}}$ is a binary variable that takes the value 1 if generator $j$ is dispatched in period $t$, and it is 0 otherwise. On the other hand, $P_{\text {Dit }}$ and $\mathrm{C}_{\text {Dit }}$ are the demand $\mathrm{i}$ power and price bid, ND is the number of demand bids, $\mathrm{R}_{\mathrm{Gj}}^{\text {up }}$ and $\mathrm{R}_{\mathrm{Gj}}^{\text {down }}$ are the values of the up and of the down ramps of generator $j$, $\mathrm{Inc}_{\min \mathrm{j}}$ is the minimum daily income required by generator $\mathrm{j}$ and $\lambda_{\mathrm{t}}$ is the market price in period $\mathrm{t}$.

$$
\begin{aligned}
& \max Z=\sum_{t=1}^{24}\left[\sum_{i=1}^{N_{D}} C_{\text {Dit }} \cdot P_{D i t}-\sum_{j=1}^{N_{G}} \sum_{m=1}^{M_{J}} C_{G j m t} \cdot P_{G j m t}\right] \\
& \text { subj } \quad 0 \leq \mathrm{P}_{\text {Dit }} \leq \mathrm{P}_{\text {Dit }}^{\text {máx }} \quad \forall \mathrm{i}, \mathrm{t} \\
& 0 \leq \sum_{\mathrm{m}=1}^{\mathrm{MJ}} \mathrm{P}_{\mathrm{Gjmt}} \leq \mathrm{P}_{\mathrm{Gjt}}^{\mathrm{máx}} \quad \forall \mathrm{j}, \mathrm{t} \\
& 0 \leq \mathrm{P}_{\mathrm{Gjmt}} \leq \mathrm{u} \text { jt } \cdot \mathrm{P}_{\mathrm{Gjmt}}^{\mathrm{máx}} \quad \forall \mathrm{j}, \mathrm{m}, \mathrm{t} \\
& \mathrm{P}_{\mathrm{Gjmt}}=\mathrm{u}_{\mathrm{jt}} \cdot \mathrm{P}_{\mathrm{Gjmt}}^{\max } \quad \forall \mathrm{j}, \mathrm{m}=1, \mathrm{t} \\
& \sum_{m=1}^{M J} P_{G j m t+1}-\sum_{m=1}^{M J} P_{G j m t} \leq R_{G j}^{\text {up }} \quad \forall j, t \\
& \sum_{\mathrm{m}=1}^{\mathrm{MJ}} \mathrm{P}_{\mathrm{Gjmt}}-\sum_{\mathrm{m}=1}^{\mathrm{MJ}_{\mathrm{J}}} \mathrm{P}_{\mathrm{Gjmt}+1} \leq \mathrm{R}_{\mathrm{Gj}}^{\text {down }} \quad \forall \mathrm{j}, \mathrm{t} \\
& \sum_{\mathrm{t}=1}^{24} \lambda_{\mathrm{t}} \cdot\left[\sum_{\mathrm{m}=1}^{\mathrm{MJ}} \mathrm{P}_{\mathrm{Gjmt}}\right] \geq \mathrm{Inc}_{\min } \mathrm{j} \quad \forall \mathrm{j} \\
& \sum_{t=1}[m=1] \geq \\
& \sum_{\mathrm{j}=1}^{\mathrm{N}_{\mathrm{G}}} \sum_{\mathrm{m}=1}^{\mathrm{MJ}_{\mathrm{J}}} \mathrm{P}_{\mathrm{Gjmt}}=\sum_{\mathrm{i}=1}^{\mathrm{ND}_{\mathrm{D}}} \mathrm{P}_{\mathrm{Dit}}
\end{aligned}
$$

This is a Mixed-Integer Linear Programming problem that generalizes the model in Section III.A. For each hour t, constraints (8) and (9) represent the limits on the buying and selling quantities of demand $i$ and generator $j$. Constraint (10) represents the limits of the selling quantity 
allocate to each block of generator $\mathrm{j}$. This constraint uses a binary variable $u_{j t}$ taking the value 1 if generator $\mathrm{j}$ is dispatched in hour t. Constraint (11) indicates that if generator $\mathrm{j}$ is dispatched in hour $\mathrm{t}$ (that is, $\mathrm{u}_{\mathrm{jt}}=1$ ), then its first block $(m=1)$ is entirely used. Constraints (12) and (13) represent the gradient condition. Constraint (14) expresses the minimum income condition for generator $\mathrm{j}$ admitting that $\lambda_{t}$ is the market price determined by the Market Operator for hour $\mathrm{t}$ and that $\mathrm{Inc}_{\min \mathrm{j}}$ is expressed by (6).

Finally, the demand/supply balance equation (15) is written for every hour $t$ of the next day. This problem can be further enlarged by including the AC power flow equations and limits on nodal voltages and on branch flows, thus building a more integrated model reflecting the activities of both the Market and the System Operators.

\section{SOLUTION ALGORITHM}

The problem $(7-15)$ together with changes on the dispatch imposed by violations of technical network constraints can be solved as follows:

- in the first place, we get the uncoupled uniform auction solution identified by the Market Operator not considering complexity conditions;

- then, complexity conditions are checked and the System Operator runs an AC power flow study for each hour to detect network violations;

- if no violations exist, the solution is technically feasible. However, if at least one violation exists, the dispatch has to be changed. To perform this change in an integrated way and to guarantee obtaining an adequate solution, we adopted a Simulated Annealing based algorithm detailed in the next paragraphs.

This solution approach has an analogy with the solution of linear optimization problems by solving in the first place a smaller problem. Then, if any of the remaining constraints not initially considered are infeasible, they are considered in a progressive way and one regains feasibility by performing iterations of the Dual Simplex Method. In maximization problems while doing these iterations, the integration of new constraints reduces the objective function and the iterative procedure stops as soon as feasibility is regained.

The initial solution of the Simulated Annealing corresponds to the set of 24 uncoupled hourly dispatches obtained by the Market Operator. Then, the algorithm proceeds as follows:

- for each hourly dispatch, we check the complexity conditions described in Section IV.A and run an AC power flow to identify over voltages and overflows;

- the set of 24 hour dispatches is then characterized by an Evaluation Function, EF. This function includes several penalty terms namely related with voltage and branch flow limits, with the minimum income condition, with up and down generator ramps and with the indivisibility condition. Apart from these terms, it also penalizes the relative difference of the values of the SWF computed for the initial uncoupled solution obtained by the Market Operator and for the current solution obtained along the Simulated Annealing. This means we want to get a final solution that minimizes this difference so that, from an economic point of view, the final schedule is as close as possible to the initial uncoupled solution identified by the Market Operator;

- once all violations that affect the current solution are known, we identify a new one in its neighbourhood using a sampling procedure. For instance, if there is a violation of an up-ramp from period t to $t+1$, the corresponding generator output can be decreased in period $\mathrm{t}+1$ and it is sampled a new one to be increased so that the balance is kept in period $t+1$. Once the new solution is built, its EF is computed and it is run the testing phase detailed in Section II;

- the algorithm runs a maximum number of iterations per temperature level. When this number is reached, the temperature is lowered by the cooling factor $\alpha$;

- finally, the algorithm stops if the number of iterations without improving the Evaluation Function reaches a pre-specified number. On the other hand, the algorithm also stops without converging if the temperature gets smaller than a minimum value or if the total number of iterations reaches a maximum pre-specified number.

\section{CASE STUDY}

\section{A. System data}

The developed algorithm was tested using a Case Study based on the IEEE 24 bus/38 branch test system originally detailed in [13]. Regarding the original data, branch flow limits were reduced to get a more stressed situation (the limit of $138 \mathrm{kV}$ branches is $150 \mathrm{MW} / 150 \mathrm{MVAr}$, for 230 $\mathrm{kV}$ branches it is $340 \mathrm{MW} / 340 \mathrm{MVAr}$ and the capacity of the transformers is $215 \mathrm{MVA}$ ). Voltage limits were set at 0.92 and $1.10 \mathrm{pu}$.

Table I. Buying bids for periods 1 to 4 .

\begin{tabular}{|c|c|c|c|c|c|c|}
\hline \multirow{2}{*}{ Bus } & \multicolumn{2}{|c|}{ Period 1 } & \multicolumn{2}{c|}{ Period 3 } & \multicolumn{2}{c|}{ Period 4 } \\
\cline { 2 - 7 } & $\begin{array}{c}\mathrm{P}_{\mathrm{gk}} \\
(\mathrm{MW})\end{array}$ & $\begin{array}{c}\text { Price } \\
\text { (€/MW.h) }\end{array}$ & $\begin{array}{c}\mathrm{P}_{\mathrm{gk}} \\
(\mathrm{MW})\end{array}$ & $\begin{array}{c}\text { Price } \\
(€ / \mathrm{MW} . \mathrm{h})\end{array}$ & $\begin{array}{c}\mathrm{P}_{\mathrm{gk}} \\
(\mathrm{MW})\end{array}$ & $\begin{array}{c}\text { Price } \\
\text { (/MW.h) }\end{array}$ \\
\hline 1 & 45.0 & 29.5 & 40.0 & 29.5 & 65.0 & 30.0 \\
\hline 2 & 75.0 & 29.0 & 70.0 & 29.0 & 92.0 & 28.0 \\
\hline 3 & 130.0 & 28.0 & 90.0 & 28.0 & 150.0 & 28.0 \\
\hline 4 & 70.0 & 27.5 & 205.0 & 27.5 & 74.0 & 26.5 \\
\hline 5 & 75.0 & 27.5 & 40.0 & 27.5 & 65.0 & 27.0 \\
\hline 6 & 120.0 & 26.5 & 95.0 & 26.5 & 126.0 & 26.0 \\
\hline 7 & 110.0 & 26.0 & 138.0 & 26.0 & 130.0 & 26.0 \\
\hline 8 & 125.0 & 25.5 & 100.0 & 25.5 & 145.0 & 22.0 \\
\hline 9 & 140.0 & 23.5 & 375.0 & 23.5 & 180.0 & 25.0 \\
\hline 10 & 210.0 & 24.5 & 135.0 & 24.5 & 215.0 & 24.5 \\
\hline 11 & 80.0 & 19.0 & 40.0 & 17.0 & 75.0 & 17.0 \\
\hline 12 & 90.0 & 15.0 & 50.0 & 15.0 & 70.0 & 15.0 \\
\hline 13 & 255.0 & 22.5 & 210.0 & 22.5 & 265.0 & 24.0 \\
\hline 14 & 185.0 & 23.5 & 270.0 & 23.5 & 325.0 & 23.5 \\
\hline 15 & 325.0 & 23.0 & 280.0 & 23.0 & 313.0 & 23.0 \\
\hline 16 & 105.0 & 22.5 & 180.0 & 22.5 & 140.0 & 22.5 \\
\hline 17 & 0.0 & 0.0 & 0.0 & 0.0 & 0.0 & 0.0 \\
\hline 18 & 265.0 & 22.0 & 210.0 & 22.0 & 240.0 & 22.0 \\
\hline 19 & 158.0 & 21.5 & 280.0 & 21.5 & 140.0 & 21.5 \\
\hline 20 & 115.0 & 15.0 & 100.0 & 21.0 & 130.0 & 21.0 \\
\hline 21 & 15.0 & 20.0 & 10.0 & 20.0 & 10.0 & 20.0 \\
\hline 22 & 10.0 & 10.0 & 5.0 & 10.0 & 5.0 & 10.0 \\
\hline 23 & 30.0 & 12.0 & 30.0 & 30.0 & 20.0 & 30.0 \\
\hline 24 & 8.0 & 30.0 & 13.0 & 17.0 & 10.0 & 15.0 \\
\hline & & & & & & \\
\hline
\end{tabular}


In this Case Study and for illustration purposes, we admitted that the 24 hour periods were grouped in 4 periods as follows: period 1 with 12 hours, periods 2,3 and 4 each of them with 4 hours. Tables I and II include the buying and selling bid data in periods 1,3 and 4 and Table III details the complexity conditions, namely the fix and variable terms of condition (6), the power of the first block of the generator bids and the values of the up and the down ramps.

Table II. Selling bids for periods 1 to 4 .

\begin{tabular}{|c|c|c|c|c|c|c|}
\hline \multirow{2}{*}{ Bus } & \multicolumn{2}{|c|}{ Period 1 } & \multicolumn{2}{c|}{ Period 3 } & \multicolumn{2}{c|}{ Period 4 } \\
\cline { 2 - 7 } & $\begin{array}{c}\mathrm{P}_{\mathrm{gk}} \\
(\mathrm{MW})\end{array}$ & $\begin{array}{c}\text { Price } \\
\text { (๕/MW.h) }\end{array}$ & $\begin{array}{c}\mathrm{P}_{\mathrm{gk}} \\
(\mathrm{MW})\end{array}$ & $\begin{array}{c}\text { Price } \\
\text { (€/MW.h) }\end{array}$ & $\begin{array}{c}\mathrm{P}_{\mathrm{gk}} \\
(\mathrm{MW})\end{array}$ & $\begin{array}{c}\text { Price } \\
\text { (€/MW.h) }\end{array}$ \\
\hline 1 & 205 & 20.00 & 260 & 20.00 & 280 & 19.50 \\
\hline 2 & 170 & 18.00 & 190 & 18.00 & 192 & 17.50 \\
\hline 7 & 190 & 8.00 & 240 & 8.00 & 230 & 8.00 \\
\hline 13 & 525 & 7.00 & 560 & 7.00 & 510 & 7.00 \\
\hline 15 & 145 & 7.80 & 200 & 7.80 & 160 & 7.90 \\
\hline 16 & 160 & 8.10 & 100 & 8.10 & 120 & 7.60 \\
\hline 18 & 290 & 4.50 & 340 & 4.50 & 305 & 3.30 \\
\hline 21 & 340 & 3.00 & 400 & 3.00 & 390 & 3.00 \\
\hline 22 & 170 & 1.00 & 230 & 1.00 & 220 & 1.00 \\
\hline 23 & 590 & 7.10 & 640 & 7.10 & 610 & 7.50 \\
\hline
\end{tabular}

Table III. Complexity constraints.

\begin{tabular}{|c|c|c|c|c|c|c|c|}
\hline \multirow[b]{2}{*}{ Bus } & \multicolumn{2}{|c|}{ Minimum Income } & \multicolumn{3}{|c|}{$\begin{array}{l}\text { Indivisibility condition } \\
\text { (first block) }\end{array}$} & \multirow{2}{*}{$\begin{array}{c}\mathrm{Up} \\
\text { ramp } \\
\text { (MW) }\end{array}$} & \multirow{2}{*}{$\begin{array}{l}\text { Down } \\
\text { ramp } \\
\text { (MW) }\end{array}$} \\
\hline & $\begin{array}{c}\text { Fix } \\
\text { term } \\
(€)\end{array}$ & $\begin{array}{c}\text { Variable } \\
\text { term } \\
(€ / \mathrm{MWh})\end{array}$ & $\begin{array}{c}\mathrm{P} 1 \\
(\mathrm{MW})\end{array}$ & $\cdots$ & $\begin{array}{c}\mathrm{P} 4 \\
(\mathrm{MW})\end{array}$ & & \\
\hline 1 & 1500 & 16 & 31 & $\ldots$ & 95 & 40 & 35 \\
\hline 2 & 2000 & 12 & 26 & $\ldots$ & 38 & 40 & 40 \\
\hline 7 & 3000 & 6 & 29 & $\ldots$ & 46 & 40 & 32 \\
\hline 13 & 2500 & 5 & 95 & $\ldots$ & 56 & 60 & 60 \\
\hline 15 & 2500 & 6 & 29 & $\ldots$ & 32 & 50 & 50 \\
\hline 16 & 1500 & 5 & 32 & $\ldots$ & 17 & 35 & 40 \\
\hline 18 & 2000 & 3 & 26 & $\ldots$ & 61 & 45 & 35 \\
\hline 21 & 2000 & 2 & 68 & $\ldots$ & 66 & 50 & 40 \\
\hline 22 & 1000 & 1 & 34 & $\ldots$ & 44 & 45 & 35 \\
\hline 23 & 2000 & 5 & 89 & $\ldots$ & 122 & 60 & 60 \\
\hline
\end{tabular}

\section{B. Market Operator results}

Using this data, the Market Operator performs four uniform price auctions not considering complexity constraints. In each of these periods, the clearing prices are 18.0, 16.0, 18.0 and 19,5 €/MW.h. As an illustration, Figure 1 presents the selling and buying aggregated curves for period 1 and Table IV details the generation schedule obtained for periods 1, 3 and 4. The global value of the Social Welfare Function corresponding to the sum of the areas between the buying and selling curves till the cleared quantity of each period multiplied by the respective duration is $1.109 .224 €$.

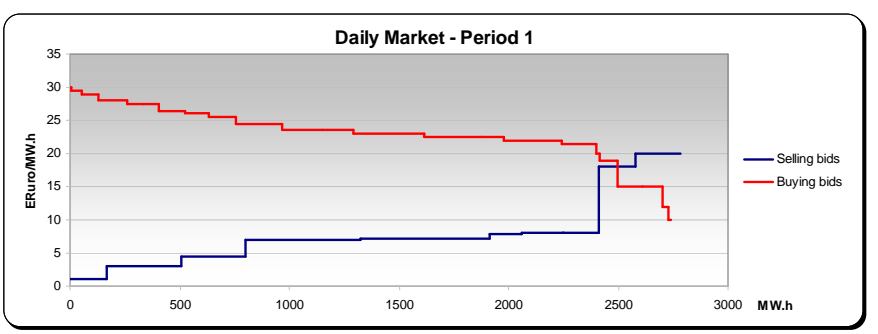

Figure 1. Results of the daily market for period 1.
Table IV. Generation values in periods 1 to 4 .

\begin{tabular}{|c|c|c|c|c|c|c|}
\hline \multirow{2}{*}{ Bus } & \multicolumn{2}{|c|}{ Period 1 } & \multicolumn{2}{c|}{ Period 3 } & \multicolumn{2}{c|}{ Period 4 } \\
\cline { 2 - 7 } & $\begin{array}{c}\mathrm{P}_{\mathrm{gk}} \\
(\mathrm{MW})\end{array}$ & $\begin{array}{c}\text { Price } \\
(€ / M W . h)\end{array}$ & $\begin{array}{c}\mathrm{P}_{\mathrm{gk}} \\
(\mathrm{MW})\end{array}$ & $\begin{array}{c}\text { Price } \\
(€ / \mathrm{MW} . \mathrm{h})\end{array}$ & $\begin{array}{c}\mathrm{P}_{\mathrm{gk}} \\
(\mathrm{MW})\end{array}$ & $\begin{array}{c}\text { Price } \\
(€ / \mathrm{MW} . \mathrm{h})\end{array}$ \\
\hline 22 & 170,0 & 1,0 & 230,0 & 1,0 & 220,0 & 1,0 \\
\hline 21 & 340,0 & 3,0 & 400,0 & 3,0 & 390,0 & 3,0 \\
\hline 18 & 290,0 & 4,5 & 340,0 & 4,5 & 305,0 & 3,3 \\
\hline 13 & 525,0 & 7,0 & 560,0 & 7,0 & 510,0 & 7,0 \\
\hline 23 & 590,0 & 7,1 & 640,0 & 7,1 & 610,0 & 7,5 \\
\hline 15 & 145,0 & 7,8 & 200,0 & 7,8 & 160,0 & 7,9 \\
\hline 7 & 190,0 & 8,0 & 240,0 & 8,0 & 230,0 & 8,0 \\
\hline 16 & 160,0 & 8,1 & 100,0 & 8,1 & 120,0 & 7,6 \\
\hline 2 & 86,0 & 18,0 & 148,0 & 18,0 & 192,0 & 17,5 \\
\hline 1 & 0,0 & 20,0 & 0,0 & 20,0 & 88,0 & 19,5 \\
\hline
\end{tabular}

C. Evaluation of the initial schedules

Using these results, the System Operator runs four AC power flow studies to check voltage and branch flow limits. The evaluation of the solution detailed in Section VI.B also includes checking the complexity conditions. Table V details the income of each generator along the trading day and the minimum income given by (6). The daily income of an unit in calculated as indicated in Section IV.A using the hourly allocated powers and hourly market prices. The minimum income uses the scheduled energy given by the addition of the energies in all periods. Each of these energies is the product of the power allocated to the generator in that period by its duration. Once the daily energy is obtained, expression (6) is used to calculate the minimum income.

Table V - Values of the daily income and of the minimum income for the initial uncoupled solution.

\begin{tabular}{|c|c|c|c|c|c|}
\hline Bus & $\begin{array}{c}\text { income } \\
(€)\end{array}$ & $\begin{array}{c}\text { fix } \\
\text { term } \\
(€)\end{array}$ & $\begin{array}{c}\text { variable } \\
\text { term } \\
(€ / \mathrm{MWh})\end{array}$ & $\begin{array}{c}\text { energy } \\
(\mathrm{MWh})\end{array}$ & $\begin{array}{c}\text { minimum } \\
\text { income } \\
(€)\end{array}$ \\
\hline 22 & 82600 & 1000 & 1 & 4600 & 5600 \\
\hline 21 & 156340 & 2000 & 2 & 8720 & 19440 \\
\hline 18 & 131070 & 2000 & 3 & 7320 & 23960 \\
\hline 13 & 226780 & 2500 & 5 & 12660 & 65800 \\
\hline 23 & 261100 & 2000 & 5 & 14580 & 74900 \\
\hline 15 & 67800 & 2500 & 6 & 3780 & 25180 \\
\hline 7 & 89060 & 3000 & 6 & 4960 & 32760 \\
\hline 16 & 60080 & 1500 & 5 & 3360 & 18300 \\
\hline 2 & 49072 & 2000 & 12 & 2696 & 34352 \\
\hline 1 & 6864 & 1500 & 16 & 352 & 7132 \\
\hline
\end{tabular}

The evaluation of the initial uncoupled schedule leads to the following results:

- violation of the minimum daily income of generator 1 and of its minimum generation limit in period 4;

- violation of the up-ramp limit of generator 1 from period 3 to period 4 ;

violation of the up-ramp limit of generator 2 from period 2 to period 3 and from period 3 to period 4;

violation of the minimum voltage limit of $0.92 \mathrm{pu}$ in buses $3,4,9,15$ and 24 in period 2;

violation of the capacity of the transformer connected to buses 9-12 in periods 2 and 3, and of the capacity of the transformer connected to buses 10-12 in period 1 ;

violation of the maximum active flow in branches 7-8 and $16-17$ in period 3 and of the maximum reactive flow in branches $1-3,15-16$ and $15-24$ in period 2 . 
Due to these violations, the initial purely economic dispatch is not feasible and so the Simulated Annealing based algorithm was used to regain feasibility.

\section{Final dispatch - Simulated Annealing}

The departing solution of the algorithm is the uncoupled set of schedules obtained by the Market Operator as detailed in Section VI.B. This solution is characterized by the Evaluation Function that includes terms related with penalties associated to the violations listed in Section VI.C. Due to all these penalty terms, the initial value of this function is 13.726.888. The Simulated Annealing used the following parameters:

- penalty coefficient assigned to the relative variation of the Social Welfare Function along the algorithm 100 ;

- max. number of iterations per temperature level 180 ;

- initial temperature - 1.0 ;

- cooling factor -0.9 ;

- max. number of iterations without improvements 180 ;

Using these parameters, the algorithm ran 788 iterations and the temperature lowered to 0.6561 . The final value of the evaluation function is 10,875 , that is, it was obtained an improvement of $13.726 .877,12$ regarding its initial value. The final solution eliminates all violations just mentioned meaning that the final value obtained for the Evaluation Function $(10,875)$ just corresponds to the penalization due to the fact that the final value of the Social Welfare Function, 1.097.160,76 €, is more reduced than the one obtained for the uncoupled solution $(1.109 .224 €)$. The final value of the Evaluation Function $(10,875)$ corresponds to the division of the reduction felt by the Social Welfare function $(12.063,24 €)$ by its initial value of for the uncoupled solution and multiplied by the penalty coefficient of 100 mentioned above.

Table VI - Values of the daily income and of the minimum income for the final solution.

\begin{tabular}{|c|c|c|c|c|c|}
\hline Bus & $\begin{array}{c}\text { income } \\
(€)\end{array}$ & $\begin{array}{c}\text { fix term } \\
(€)\end{array}$ & $\begin{array}{c}\text { variable } \\
\text { term } \\
(€ / \mathrm{MWh})\end{array}$ & $\begin{array}{c}\text { Energy } \\
(\mathrm{MWh})\end{array}$ & $\begin{array}{c}\text { minimum } \\
\text { income } \\
(€)\end{array}$ \\
\hline 22 & 80500,4 & 1000 & 1 & 4476 & 5476 \\
\hline 21 & 152811,6 & 2000 & 2 & 8518 & 19036 \\
\hline 18 & 128744 & 2000 & 3 & 7187,2 & 23561,6 \\
\hline 13 & 225277,6 & 2500 & 5 & 12574,4 & 65372 \\
\hline 23 & 258501 & 2000 & 5 & 14429,2 & 74146 \\
\hline 15 & 65840,4 & 2500 & 6 & 3666,4 & 24498,4 \\
\hline 7 & 87487,8 & 3000 & 6 & 4870 & 32220 \\
\hline 16 & 59675,2 & 1500 & 5 & 3334,8 & 18174 \\
\hline 2 & 58698,2 & 2000 & 12 & 3256 & 41072 \\
\hline 1 & 13230,4 & 1500 & 16 & 716 & 12956 \\
\hline
\end{tabular}

As indicated above, the value of the Social Welfare Function gets reduced by $12.063,24 €$. This reduction indicates that considering coupling and network constraints leads to an over cost. In fact, the value of the Social Welfare Function obtained for the uncoupled solution is the best that could be obtained since it reflects a pure economic dispatch only determined by the simple buying and selling bids. After considering new constraints in the problem, it is clear that the final value of the Social Welfare Function will be not larger than the one obtained for the uncoupled problem. The above difference can also be interpreted as the distance between the final solution and the initial uncoupled one obtained by the Market Operator. Finally, Table VI presents the corresponding values of the daily income and of the minimum income of each generator for the final generation schedule.

\section{CONCLUSIONS}

In this paper we presented a multiperiod optimization model that includes complexity conditions and network technical constraints to obtain the Market Operator bidbased dispatch. The problem is mixed integer given the presence of binary variables to represent the use of the first block of generator selling bids. Given this mixed integer nature, we adopted Simulated Annealing to solve this problem, namely to ensure a more systematic search procedure together with the possibility of escaping from local minima when compared with other gradient based approaches in the literature. As shown in the case study, the Simulated Annealing approach proved to be very efficient suggesting that this type of approaches can be of interest for market agents and operators in order to simulate the market and system operation.

\section{REFERENCES}

[1] T. Peng, K. Tomsovic, "Congestion Influence on Bidding Strategies in an Electricity Market", IEEE Trans. on Power Systems, vol. 18, no.3, pp. 1054 - 1061, August 2003.

[2] G. Hamoud, I. Bradley, "Assessment of Transmission Congestion Cost and Locational Marginal Pricing in a Competitive Electricity Market”, IEEE Trans. on Power Systems, vol. 19, no. 2, pp. $769-$ 775, May 2004.

[3] A. Kumar, S. Srivastava, A. Singh, "A Zonal Congestion Management Approach Using Real and Reactive Power Rescheduling”, IEEE Trans. on Power Systems, vol. 19, no. 1, pp. $554-562$, February 2004.

[4] S. Oren, A. Ross, "Economic Congestion Relief Across Multiple Regions Requires Tradable Physical Flow-Gate Rights", IEEE Trans. on Power Systems, vol. 17, no. 1, pp. 159- 165, February 2002.

[5] R. Méndez, H. Rudnick, "Congestion Management and Transmission Rights in Centralized Electric Markets", IEEE Trans. on Power Systems, vol. 19, no. 2, pp. 889 - 896, May 2004.

[6] N. Pamudji, R. Kaye, H. Outhred, "Network Effects in Competitive Electricity Industry: Non-linear and Linear Nodal Auction Models", in Proc. of IEEE Stockholm Power Tech, Sweden, pp. 698-703, 1995.

[7] J. Arroyo, A. Conejo, "Multiperiod Auction for a Pool-Based Electricity Market", IEEE Trans. on Power Systems, vol. 17, no. 4, pp. $1225-1231$, November 2002.

[8] A. Motto, F. Galiana, F., "Coordination in Markets with Nonconvexities as a Mathematical Program With Equilibrium Constraints - Part I : A Solution Procedure", IEEE Trans. Power Systems, vol. 19, no. 1, pp. 308 - 316, February 2004.

[9] E. L. Miguelez, L. R. Rodriguez, et al, "A Practical Approach to Solve Power System Constraints with Application to the Spanish Electricity Market", IEEE Trans. on Power Systems, vol. 19, no. 4, pp. 2029 - 2037, November 2004

[10]S. Kirkpatrick, C. Gelatt, M. Vecchi,"Optimization by Simulated Annealing", Science, vol. 220, pp. 671 - 680, no. 4598, May 1983.

[11]E. Aarts, J. Korst, Simulated Annealing and Boltzman Machines, John Wiley \& Sons, New York, 1990.

[12] Iberian Energy Market Operator - Spanish Pole, OMEL, "Electricity Market Activity Rules", (in Spanish), Tech. Rep., available in www.omel.es, April 2001.

[13] Task Force of Application Probabilistic Methods Subcommittee, "IEEE Reliability Test System", IEEE Trans. on PAS, vol. PAS-98, no. 6, pp. 2047 - 2054, November 1979. 